\title{
As piqueteiras: \\ mulheres e participação política na greve metalúrgica de 1979 no Rio de Janeiro
}

\author{
Marco Aurélio Santana* \\ Alexandre Barbosa Fraga**
}

\section{Introdução}

Ao longo da história do movimento operário internacional, devido à sua centralidade no processo de produção capitalista, a categoria metalúrgica esteve presente em momentos importantes. Impossível traçar uma trajetória do movimento da classe trabalhadora sem que os metalúrgicos ganhem lugar de destaque. Por certo, acabaram se criando algumas imagens acerca dessa ocupaçáo. Ela figurava quase como um modelo do que seriam os trabalhadores fabris, suas formas de organizaçáo e maneiras de fazer política. Nesse sentido, as mulheres ficaram bastante obscurecidas em termos de sua presença na categoria, não apenas por seu reduzido número nesse tipo de setor, mas, sobretudo, em razão das imagens criadas em torno dele, que o viam de forma extremamente masculinizada.

No caso brasileiro, isso não foi diferente. A categoria metalúrgica ocupou lugar de destaque no cenário industrial do país, além de assumir o papel de certo

Professor do Departamento de Sociologia e do Programa de Pós-Graduação em Sociologia e Antropologia (PPGSA) da Universidade Federal do Rio de Janeiro (UFRJ), onde coordena o Núcleo de Estudos Trabalho e Sociedade no Instituto de Filosofia e Ciências Sociais da mesma universidade (NETS/IFCS-UFRJ). E-mail: msantana@ifcs.ufrj.br.

" Pós-Doutorando em Sociologia pelo Programa de Pós-Graduação em Sociologia e Antropologia (PPGSA) da Universidade Federal do Rio de Janeiro (UFRJ) e coordenador do Núcleo de Estudos Trabalho e Sociedade no Instituto de Filosofia e Ciências Sociais da mesma universidade (NETS/IFCS-UFRJ). E-mail: alexbfraga@yahoo.com.br. 
modelo em termos do que seriam a classe trabalhadora fabril, suas formas de vida e trabalho, bem como de organização e mobilização. Além desse tipo de viés, somam-se outros, por exemplo, aquele que baseia, quase exclusivamente, sua visão na proeminência de locais como São Paulo (SP), por óbvia e inegável relevância política, econômica e financeira, centralizando por demais a perspectiva e não enfatizando outras experiências de relevo, como a do Rio de Janeiro (RJ).

Apesar da importância da greve metalúrgica de 1979 do Rio de Janeiro para a história operária, há poucas publicaçóes acadêmicas que a analisaram (Torreão, 1986; Martinho, 2017), as quais podem ser somadas a um livreto, de tom memorialístico, produzido pelo Centro Cultural dos Trabalhadores (CECUT), em 1981. Essas três pesquisas entrevistaram, respectivamente, 31, 6 e 19 metalúrgicos da época, dos quais 8 (26\%), 1 (17\%) e 3 (16\%) eram mulheres. Portanto, em geral, essa produção está centrada na visão dos homens sobre os acontecimentos que marcaram a greve, além de não ter se preocupado em problematizar as questôes de gênero. Em relação a isso, Torreão (1986) é exceção, mas, ainda que tenha levado em consideração a participação feminina na greve, o foco de seu trabalho foi o papel das lideranças.

Nesse sentido, este artigo tem como objetivo contribuir para a compreensão da greve metalúrgica de 1979 do Rio de Janeiro, juntando-se a essas produçóes já existentes, mas sob o ponto de vista específico das mulheres que fizeram parte desse movimento, seja na liderança ou na base, e do papel que desempenharam nele, de forma a trazer uma perspectiva que dê visibilidade às açôes realizadas por elas naquele contexto.

Interessa-nos entender como foi possível, após quinze anos sem nenhuma mobilizaçáo de monta, a categoria ter se organizado e conseguido parar a produção, impactando esse setor econômico no estado. Na visão das trabalhadoras que participaram, quais as reivindicaçóes da categoria naquele momento e por que a greve teve tanta força? As mulheres atuaram nas articulaçóes e organizaçóes da greve e fizeram parte dos piquetes nas portas das fábricas? Por meio de quais estratégias buscaram articular a militância à esfera reprodutiva (cuidado dos filhos e dos afazeres domésticos, por exemplo)?

Com o intuito de atingir esse objetivo, a pesquisa valeu-se da metodologia da História Oral. Tendo em vista as perguntas formuladas, essa metodologia revelou-se a mais adequada e promissora. As fontes escritas existentes sobre a greve, como as atas das assembleias, os panfletos distribuídos e os jornais da categoria metalúrgica e da grande imprensa, trazem informaçóes sobre os acontecimentos que se desenrolaram naquela ocasião, mas não são suficientes. Primeiramente, porque nelas encontramos apenas a face mais pública dessa ação coletiva, e não os seus bastidores, tornando-se invisíveis a atuação das mulheres na manutenção da greve e as suas estratégias de articulação entre militância e responsabilidades 
familiares. Em segundo lugar, porque, como minoria na categoria e entre as lideranças, essas trabalhadoras, em geral, não tiveram suas opiniōes e posiçóes registradas nessas fontes escritas, bem como pouco se sabia a respeito da presença delas nos inúmeros piquetes que marcaram aquela greve.

Portanto, o uso da História Oral permitiu olhar essa ação coletiva sob um novo ângulo: o das mulheres que dela participaram. Seguindo essa metodologia, procurou-se lidar com um conjunto de cuidados necessários para o registro das experiências vividas por essas trabalhadoras e para a reflexão sobre os sentidos e interpretaçôes dados por elas a essas vivências (Ferreira; Amado, 2006); avaliar, no decorrer da pesquisa, as articulaçóes entre a memória individual sobre a greve de cada uma dessas mulheres e a memória coletiva construída pelo conjunto das entrevistadas (Halbwachs, 1990); e tomar os esquecimentos, os silêncios e as reinterpretações de um passado vivido por elas há quarenta anos como dados sobre os quais é preciso refletir (Pollak, 1989).

De novembro de 2017 a setembro de 2019, foram entrevistadas onze mulheres que tiveram parte ativa na greve de 1979 (ver fontes orais ao final deste artigo). Para isso, montou-se um conjunto de entrevistas pela técnica da "bola de neve" ou de indicação sucessiva, por meio da qual a rede foi sendo formada pela sugestão de cada nova partícipe, além de ter contado com o apoio de um ex-diretor do sindicato dos anos 1980, o qual possibilitou o contato com algumas delas. O roteiro das entrevistas contemplou os seguintes eixos temáticos: (1) família, (2) entrada na categoria, (3) militância, (4) participação na greve de 1979 e (5) pósgreve até hoje. Dessa forma, foi possível levá-las a refletir sobre suas trajetórias de vida, o trabalho como metalúrgicas, as causas pelas quais se mobilizaram e a perspectiva que elas têm a respeito da greve de 1979.

Devido ao seu objetivo específico, este artigo enfatizou, sobretudo, aquilo que foi narrado por elas no eixo 4. Para responder às questóes formuladas e interpretar o material de pesquisa, utilizou-se como aporte teórico parte tanto dos estudos do campo historiográfico intitulado História das mulheres e das relações de gênero (Soihet; Pedro, 2007) quanto da produção da Sociologia que pretendeu relacionar classe e gênero. Sendo assim, procurou-se refletir sobre as esferas produtiva e reprodutiva, as práticas, as resistências e as lutas, de forma a observar a atuação das mulheres como sujeitos ativos e políticos, permitindo, entâo, ampliar as visóes sobre o passado.

\section{9 e o ciclo de mobilizações operárias}

A passagem entre as décadas de 1970 e 1980 é marcada, no campo político 
brasileiro, pelo processo de flexibilização do regime militar implantado no país em 1964. Se a estratégia de distensão política proposta no governo de Ernesto Geisel (1974-1978) dava seus primeiros passos a partir de 1974, é desde o primeiro ano do governo de seu sucessor, João Figueiredo (1979-1984), que ela se efetiva por meio de instrumentos tais como a Lei de Anistia e a chamada reforma partidária, com o fim do bipartidarismo compulsório imposto pelo Ato Institucional de n. ${ }^{\circ}$ 2, de $1965 .{ }^{1}$ Nesse período, há o ressurgimento do movimento sindical brasileiro, o qual, depois de muitos anos de trabalho silencioso no interior das fábricas e de algumas tentativas mais visíveis de contestação, reapareceu em céu aberto buscando mais espaços para a conquista das reivindicaçóes dos/as trabalhadores/as.

Obviamente que o regime não ficou impassível ao ascenso dos movimentos sociais. Impondo uma estratégia de transição "lenta e gradual", por exemplo, os militares intervieram no Sindicato dos Metalúrgicos do $\mathrm{ABC}$, presidido por Luiz Inácio Lula da Silva, o Lula, e enquadraram seus dirigentes na Lei de Segurança Nacional (LSN), quando das greves que eclodiram naquela base operária. Contudo, os militares não tinham muito mais fôlego para impedir que a sociedade brasileira, em geral, e a classe trabalhadora, em particular, fossem reconquistando seus direitos. A greve metalúrgica do $\mathrm{ABC}$ paulista que irrompeu em 1978 tornou-se um divisor de águas no período. Ela teve grande relevância para o movimento dos/as trabalhadores/as e para a sociedade, já que demonstrava sua capacidade de organização, mobilização e disposição de luta, ainda que diante do temível regime militar.

Nesse sentido, o movimento operário e sindical brasileiro experimentou, no fim da década de 1970, um momento marcante para sua história. Submergido após o duro impacto promovido pelo golpe militar de 1964, que lhe havia deixado pouco ou quase nenhum espaço de manobra, o sindicalismo de corte progressista emergiu, cobrando a ampliação dos espaços para a representaçáo dos interesses da classe trabalhadora. $\mathrm{Na}$ inflexão da ditadura militar, que desde meados da década de 1970 já se propunha uma estratégia de flexibilização do regime em marcha lenta, gradual e segura, a sociedade brasileira foi reconquistando seus espaços de participação política. Vivendo um ambiente de efervescência, ela viu surgirem inúmeros movimentos sociais que foram pavimentando o caminho para o processo de redemocratização e acelerando a crise do regime militar (Krischke, 1982; Sader, 1988).

Entre esses movimentos, podem ser listados o estudantil, o de mulheres, o de bairros e o contra a carestia. Articulados ou náo ao movimento sindical, os

1 Disponível em:<planalto.gov.br/ccivil_03/ait/ait-02-65.htm>. Acesso em: 12 dez. 2020. 
movimentos sociais, em seu conjunto, engrossaram o caldo da luta democrática do período. Esses embates tiveram na classe trabalhadora um sólido ponto de sustentação. Quando os/as metalúrgicos/as do $\mathrm{ABC}$ paulista entraram em greve em 1978, abrindo caminho para a paralisação que se seguiu em outras categorias, eles romperam com os limites estreitos estabelecidos pela lei antigreve, com o "arrocho salarial" e com o silêncio geral ao qual havia sido forçada a classe trabalhadora pelo menos desde as greves de Contagem (MG) e Osasco (SP), ocorridas em 1968 (Weffort, 1972; Santana, 2001). Com isso, eles impactaram alguns dos pilares de sustentação política e econômica da ditadura militar.

Após a greve de 1978, tornaram-se possíveis outras mobilizaçóes, em um processo que se consolidou e ampliou com as greves de metalúrgicos/as em $1979 \mathrm{e}$ 1980 , às quais, em volume ainda maior do que na anterior, incorporaram-se outras categorias em todo o país, tais como bancários/as, petroleiros/as, professores/ as, ferroviários/as e construção civil. Nesse sentido, o ano de 1979 é um marco importante, significando um teste para o ressurgente movimento sindical, o qual sinalizou para os movimentos sociais em geral as possibilidades de luta no interior do regime ditatorial. Nesse contexto, inúmeras categorias profissionais deslancharam seus movimentos reivindicativos. É no bojo desse processo de ciclo de mobilizaçóes que também os/as metalúrgicos/as do Rio de Janeiro, no ano de 1979, viram suas bases se moverem, efetivando sua primeira grande greve desde o início dos governos militares.

\section{"Tá com medo, seu patrão": a dupla participação das mulheres na greve de 1979}

Um olhar generificado para o mundo do trabalho, na historiografia e na literatura sociológica, já percorreu, no Brasil, pelo menos cinquenta anos, se considerarmos como marco o livro pioneiro de Saffioti (1969). Nele, a autora reflete sobre a condição da mulher na sociedade capitalista, a qual é impactada não apenas pela exploração de classe social, mas pelo fator sexo, que, uma vez combinados, levam a desigualdades na estrutura ocupacional. Ao longo das décadas seguintes, a pesquisa sobre a relação entre gênero e trabalho e a respeito da participação feminina nas lutas e greves teve contribuiçóes importantes tanto no campo historiográfico da História das mulheres e das relaçôes de gênero (Pena, 1981; Blanco, 1982; Leite, 1984; Soihet, 1989; Del Priore, 1997) quanto no campo da Sociologia (Blay, 1978; Souza-Lobo,1991; Castro, 1992).

Ao introduzirem a questão de gênero, essas obras, sobretudo as das décadas de 1970 e 1980, andaram na contramão da produção acadêmica sobre trabalho, 
uma vez que esta estava centrada em uma visão homogênea da classe trabalhadora (homem, industrial e branco), para a qual as mulheres tornavam-se invisíveis. Essa nova perspectiva queria mostrar que "a classe operária tem dois sexos", como sintetizou Souza-Lobo (1991) no título de seu livro, isto é, as classes sociais são necessariamente atravessadas pela dimensão de gênero. Além disso, a esses dois marcadores da diferença ainda é incorporado o de raça, já presente em Saffioti (1969), demonstrando cada vez mais que a articulação entre classe, gênero e raça é estruturante da dinâmica capitalista. A imbricação entre essas três dimensões, separáveis apenas no plano analítico, posteriormente foi conceituada como "nó" das contradiçóes (Saffioti, 1997), interseccionalidade (Crenshaw, 2002) e consubstancialidade das relaçôes sociais (Kergoat, 2010).

Algumas pesquisas sobre relaçóes de gênero, especificamente no trabalho metalúrgico (Pereira, 2004; Sampaio, 2007; Lapa, 2019), ressaltaram justamente o que foi observado por toda aquela literatura mais geral citada: sendo as trabalhadoras ao mesmo tempo exploradas e oprimidas, e existindo relaçóes assimétricas entre mulheres e homens, as situaçôes vivenciadas e os sentidos atribuídos a estas, devido à articulação entre classe e gênero, diferem entre metalúrgicos e metalúrgicas. Primeiro, porque, ainda que façam parte desse mesmo setor, as mulheres são minoria e estão mais presentes no segmento eletroeletrônico e automotivo e menos no naval, de máquinas e equipamentos, e siderúrgico (Dieese, 2015). Segundo, porque, sendo o trabalho doméstico e o cuidado dos filhos atribuídos socialmente às mulheres de forma predominante, muito provavelmente há uma conformação desigual do modo como metalúrgicos e metalúrgicas articulam trabalho e família e do tempo que podem dedicar, por exemplo, à militância.

Essas diferenças acabam, então, por influenciar a construção da ação política desses/as trabalhadores/as. Sendo assim, faz sentido analisar a greve metalúrgica de 1979 do Rio de Janeiro, como fizeram CECUT (1981), Torreão (1986) e Martinho (2017), mas também especificamente, como propomos aqui, pelo ponto de vista das mulheres que participaram dela, de forma abservá-la por outros ângulos. Das onze entrevistadas em nossa pesquisa, nove eram metalúrgicas, uma integrante do movimento estudantil e outra do movimento operário popular à época. A presença não apenas de metalúrgicas entre os depoimentos de quem esteve na greve reflete a articulação de várias categorias de trabalhadores/as e movimentos sociais do Rio de Janeiro, bem como o apoio mútuo nas mobilizaçóes realizadas.

Como já observado, pelo menos a partir da metade da década de 1970, houve uma ebulição de movimentos sociais, da qual o estudantil e o de bairro faziam parte destacada. Junto à metalúrgica, várias categorias de trabalhadores/ as passaram a fazer greve também. Como é perceptível nos relatos abaixo, esses 
esforços coletivizados davam força a cada movimento singular, integrando-os a uma rede que testava os limites e acelerava a crise do regime militar.

No movimento estudantil, eu comecei em 1979. Participei pelo movimento da AMES [Associação Metropolitana dos Estudantes Secundaristas], que era o movimento secundarista. Eu estava participando da greve dos professores, porque era estudante. A gente estava na época de reconstrução do movimento estudantil. $\mathrm{Na}$ dos metalúrgicos, eu fui mais porque era greve, precisava de gente para ajudar nos piquetes, distribuir material. Eu acho que cheguei a falar uma vez, dando apoio dos estudantes, mas o principal ali eram as metalúrgicas falarem. (Jaqueline Loureiro, 2018).

Desde que eu vou morar na favela sozinha, que foi final de 1975, início de 1976, eu já estou toda envolvida no movimento operário popular [...]. Tinha gente que achava que eu era metalúrgica. Eu vivia no sindicato. Era levando os operários para as assembleias. Ia lá convencê-los disso, na porta de fábrica. (Georgina dos Santos, 2018).

Tal efervescência conectava, ainda, o que estava acontecendo no Rio de Janeiro aos movimentos de outros estados. Durante o regime militar brasileiro, a segunda metade da década de 1970 ficou marcada, em relação ao movimento operário, pelo surgimento do chamado novo sindicalismo, cujas bandeiras, além das pautas econômicas, foram, entre outras, a busca de ruptura com a legislação corporativa e a liberdade de organização sindical. Esse movimento, fruto e motor do ascenso mobilizatório do período, espraiou-se para diferentes cidades e categorias profissionais, transformando-se em um dos mais longos e vigorosos ciclos de contestação da história da classe trabalhadora brasileira.

Nesse sentido, como as mulheres entrevistadas são unânimes em afirmar, não resta dúvida de que a greve geral da categoria metalúrgica do Rio de Janeiro de 1979 , assim como outras, foi influenciada pelas greves do ABC paulista, iniciadas no ano anterior, inclusive com a circulação de militantes e lideranças entre elas:

Eu acho que o principal gancho foi de lá. $\mathrm{O} A B C$ pra gente foi um abc mesmo de abertura não só para o Rio de Janeiro, mas para outros locais. Os trabalhadores, por verem outros se levantarem, tomaram coragem naquela época de também irem à luta. Incentivou muito o movimento sindical de diversas categorias. (Edinalva Menezes, 2017).

Toda influência. Tanto que nós fomos até para Sáo Paulo e participamos de algumas assembleias lá em São Bernardo. O Sindicato dos Metalúrgicos 
fez caravana para São Bernardo do Campo [...]. Para saber como as pessoas estavam se movimentando, quais eram as principais lideranças que falariam nas assembleias, o que elas podiam trazer de bom para gente. $\mathrm{O}$ que a gente podia aprender. $\mathrm{Na}$ verdade, era um aprendizado. Era uma espécie de formação e de informação do que estava acontecendo em São Bernardo. Era um ajudando o outro [...]. A gente ia lá para assistir. Ia lá beber na fonte [...]. A gente sempre fazia esse intercâmbio de informaçóes. E sempre participava lá. E sempre vinha algum companheiro também de São Paulo participar das nossas assembleias do Rio de Janeiro. (Telma do Amaral, 2017).

As greves do ABC paulista, assim como as da FIAT em Xerém, no Rio de Janeiro, de 1978 e 1979, ambas vitoriosas na reivindicaçáo de aumento salarial, serviram de inspiraçáo e indicaram aos trabalhadores e às trabalhadoras da metalurgia ser possível fazer uma greve geral da categoria. O Sindicato dos Metalúrgicos do Rio de Janeiro, até o ano de 1975, estava sob intervenção, uma vez que a chapa oposicionista vitoriosa nas eleições para a direção, organizada por uma frente de esquerdas, foi impedida de tomar posse por ter nomes de lideranças "queimadas" junto ao Ministério do Trabalho. Para evitar novas intervençóes, os grupos de oposição sindical apostaram, nas eleiçóes seguintes de 1975 e 1977, em jovens lideranças, com representatividade, mas fora do radar do regime, e conseguiram elegê-las e vê-las assumir (Martinho, 2017).

Em 1977, foi eleito Oswaldo Pimentel, funcionário da FIAT e membro da sua comissão de fábrica. Ainda que, em pouco tempo, setores de oposição, que participaram e ajudaram a eleger essa diretoria, tenham com ela se desencantado e a criticado (Martinho, 2017), fato é que, após longo período de intervenção do regime militar na entidade, havia uma diretoria sindical de corte mais democrático, que conseguiu mesmo agregar setores progressistas em suas atividades. Isso pôde ser sentido nas assembleias que voltaram a atrair um volume cada vez maior de operários/as enchendo náo apenas o auditório da entidade, mas transbordando para a Rua Ana Nery, em São Cristóvão.

A nova composição na direção sindical deu, portanto, sua parte de contribuição para esse processo de organização e mobilizaçáo. Tendo em mente $1^{\text {o }}$ de outubro como a data-base da categoria, houve um esforço para se preparar com meses de antecedência para esse momento, por meio de três iniciativas. A primeira foi uma campanha de sindicalização que percorreu portas de fábrica com o objetivo de trazer dez mil novos/as trabalhadores/as da metalurgia ao sindicato e alcançou $70 \%$ dessa meta. A segunda, iniciativa da oposição, foi a criação da Comissão Executiva de Salário (CES), que teve como objetivo preparar a lista de reivindicaçóes que seria levada às negociaçôes com os patróes. Por fim, a terceira, ideia da CES, foi a divisão do Rio de Janeiro em treze áreas, Nova Iguaçu, Caxias, 
Campo Grande, Guadalupe, Jardim América, Inhaúma, Avenida Brasil, Vicente de Carvalho, Área Naval, Área dos Estaleiros, Jacaré, Centro-Sul e Jacarepaguá, de forma a facilitar e intensificar o trabalho de mobilização em nível local para a campanha salarial, integrando os membros das fábricas de um mesmo lugar para reuniōes de área. Com essas medidas, as oposições podiam ir "esquentando" as bases e acompanhando de perto a movimentação da direção sindical.

A greve de 1979 da categoria metalúrgica do Rio de Janeiro teve início em uma terça-feira, 11 de setembro, à noite, quando, em assembleia com mais de dez mil pessoas, foi recusada a proposta patronal de aumento de $71 \%$. Nesse sentido, a greve, que estava sendo pensada para início de outubro, foi antecipada, de forma a coincidir com a dos/as bancários/as e a dos/as professores/as, buscando impulsionar uma greve geral da classe trabalhadora no estado. A efetividade em parar a produção, alcançada no dia seguinte, certamente se tornou possível devido a essas estratégias prévias, com destaque para a organização por áreas, nas quais a greve de fato se sustentou e de onde vinham propostas para a CES, discutidas nas reuniōes locais.

Assim que acabou a assembleia, as coordenaçóes responsáveis por cada regiáo reuniram-se com os/as demais grevistas de cada localidade para combinar os piquetes que seriam iniciados ainda de madrugada. Segundo uma piqueteira,

Nós dividimos o Rio de Janeiro em áreas. Parece que eram treze áreas. E cada área ficava sob a responsabilidade de determinadas pessoas. $\mathrm{E}$ a minha área era aqui da Avenida Brasil. E tinham os trabalhadores responsáveis por cada área dessas. No caso, os piquetes. Nós dividimos para poder dar conta da manutenção de toda a paralisação. (Carminda Ferreira, 2017).

A principal reivindicação da categoria era o aumento de $83 \%$ no salário. Além disso, pleiteava estabilidade para delegados sindicais e comissóes de fábrica, adicional de insalubridade calculado sobre o ganho real, uniformes e sapatos gratuitos, equiparação salarial, 1/12 a mais na carteira para cada mês de trabalho na hora da demissão, férias em dobro, redução da jornada de trabalho para 40h semanais, data-base em $1^{\circ}$ de agosto de 1979 e desconto opcional de $1 \%$ do salário, em favor do sindicato. As entrevistadas chamaram atenção, ainda, para uma reivindicação que interessava muito às mulheres: creches em todas as empresas.

Já tinha na pauta principalmente a creche. A creche para as mulheres dentro da pauta de negociação com os patróes. A pauta da mulher metalúrgica era a questão da creche. Creche para as fábricas. Aí começava a discussão, com mais de 100 empregados, mais de 30 empregados... (Maria Inês Guimarães, 


\section{7).}

No dia 12, quarta-feira, antes que o primeiro turno das fábricas tivesse início, os piquetes começaram a ser realizados. A ação cobriu amplo espectro e chegou a paralisar de $80 \%$ a $90 \%$ dos trabalhadores e trabalhadoras, o que significou mais de 200 mil dos/as 250 mil metalúrgicos/as do Rio de Janeiro (CECUT, 1981), quando conseguiram parar todos os estaleiros navais e as maiores indústrias do setor. Após quinze anos sem mobilizaçôes desse porte, a base metalúrgica mostrava todo o seu descontentamento.

Os piquetes consistiam em grupos de trabalhadores/as que ficavam em frente aos portôes das fábricas, de mãos dadas, convencendo os/as colegas a aderirem à greve e, no limite, impedindo fisicamente que entrassem. Mais trabalhadores/ as iam chegando e incorporavam-se ao semicírculo formado, avolumando a mobilização. De tempos em tempos, era entoada em uníssono a música da greve, "Tá com medo, seu patrão", que enfatizava a principal reivindicação, ${ }^{2}$ também presente no lema " $1,2,3$, queremos 83 ".

Das onze entrevistadas, dez atuaram como piqueteiras, como foram chamadas. Essa participação foi muito importante sobretudo porque algumas fábricas e/ou setores delas eram majoritariamente femininos, como a General Eletric (GE), no bairro do Jacaré, e a Standard Elétrica, em Vicente de Carvalho. Portanto, como ressalta a piqueteira Edinalva, era mais efetivo que as mulheres falassem com suas companheiras, o que articulava toda uma rede feminina nesse processo.

Era dando as mãos, segurando a mão do outro, não deixando ninguém passar. Quando chegou o horário de entrada, nós nos mantivemos firmes. Eu me lembro de que em um dos piquetes, aqui em São Cristóvão, a gente estava de mão dada e o patrão chamando o pessoal para entrar. A gente não deixava. Aí eles chamaram a polícia [...]. Onde tinha mais mulher na fábrica, a gente colocava mais mulher no piquete. Onde tinha mais homem, botava mais homem. Trabalhamos dessa forma. (Edinalva Menezes, 2017).

O patronato metalúrgico surpreendeu-se com a força da greve operária e iniciou sua reação. Chamou a Polícia Militar (PMERJ) para impedir os piquetes e solicitou ao Ministério do Trabalho que a greve fosse considerada ilegal. No entanto, a polícia

2 A letra completa, ainda lembrada pela maioria das entrevistadas: "Tá com medo, seu patrão/ Chegou a hora do peão/ A gente berra, a gente grita/ Pega o dinheiro, estica/ Mas ele não dá/ Chega prá lá/ Assim não dá/ Ou me dá 83/ Ou não vão mais trabalhar/ Há! Há! Há! Eu não vou mais trabalhar!/ Há! Há! Há! Eu não vou mais trabalhar!" 
não atendeu devidamente aos chamados dos empresários, pois já estava ocupada com a greve da categoria bancária (Torreão, 1986, p. 32). No dia 13, quinta-feira, os piquetes continuaram com muita força, praticamente com paralisação total em quase todas as fábricas. $\mathrm{O}$ movimento, com centenas de pessoas, parou algumas ruas para impedir que os ônibus das empresas, levando trabalhadores/as, chegassem aos seus destinos.

No dia seguinte, sexta-feira, o Tribunal Regional do Trabalho (TRT) julgou a greve ilegal e concedeu um reajuste de $46 \%$, o índice oficial, mas, esperando que empregadores e empregados/as chegassem a um acordo, a reunião foi adiada. Os patróes fizeram uma nova proposta: em vez de $71 \%$, seriam $73 \%$ de aumento escalonado. Além disso, ofereceram a distribuição gratuita dos uniformes e a ampliação da estabilidade da trabalhadora de três para quatro meses após o parto. Em nova assembleia lotada, dessa vez à tarde, a direção sindical defendeu a aceitação desse acordo. Em oposição, a CES foi a favor de prosseguir com a greve até obter os $83 \%$, concepção que teve concordância da grande maioria dos/as presentes, o que significou sua continuidade.

Em cada momento da mobilizaçáo grevista era perceptível a participaçáo feminina. Podiam ser vistas mulheres em quase todos os piquetes. Essa atuação colocava para muitas delas, sobretudo as que tinham crianças pequenas, o desafio de combinar as açóes do movimento ao cuidado da casa e dos filhos. A articulação entre trabalho e família e, nesse caso específico, entre militância e família é uma questáo que certamente diz respeito também aos homens. Afinal de contas, a inserção deles na metalurgia e na greve apenas é possível se estiverem com a esfera reprodutiva (alimentação, higiene, roupa, descanso, cuidado dos filhos) resolvida de alguma forma, seja responsabilizando-se diretamente por ela, seja delegando-a a outra pessoa (Hirata; Kergoat, 2008).

No entanto, a existência de uma divisão sexual do trabalho, que atribui majoritariamente às mulheres os afazeres domésticos e o cuidado dos filhos, acaba por apresentá-las ao modelo da conciliação, no qual cabe quase que exclusivamente a elas articular as atividades domésticas às metalúrgicas, enquanto muitos de seus maridos e colegas de trabalho ficam responsáveis apenas pela esfera produtiva, delegando às esposas a reprodutiva, inseridos que estão no modelo tradicional (homem provedor e mulher cuidadora) ou de conciliaçáo (homem provedor e mulher provedora e cuidadora) (Hirata; Kergoat, 2007).

Esse dilema foi vivenciado por Maria Amélia, única das entrevistadas que não foi piqueteira. Assim como ela, o companheiro também era metalúrgico, e tinham uma filha de quatro anos. Então, uma questão estava colocada: como ambos poderiam participar dos piquetes? Era preciso encontrar alguma solução que permitisse a articulação entre militância e esfera reprodutiva. Ficou resolvido que ele participaria 
dos piquetes e que ela também daria sua contribuição, mas em uma função possível de ser realizada junto ao cuidado da filha: o apoio à greve. Observa-se, então, nesse caso, uma divisão sexual do trabalho de organização dessa ação coletiva.

Eu estava com a minha filha pequena. Ela tinha três e meio, quatro anos. Então, eu não participei dos piquetes, que o pessoal acordava de madrugada e ia. Eu participava dentro do sindicato. Eu ia para o sindicato. Na organização de mantimentos, na organização de lanches, na organização do material. Eu fiquei no apoio, porque aí a minha filha podia ficar comigo ali também. Ela ficou comigo o tempo todo. Fiquei eu e outras mulheres também. Tinham as piqueteiras, mas tinham as mulheres que ficavam ali dentro organizando. (Maria Amélia de Aquino, 2018).

Isso significa que, ainda que os piquetes, assim como as assembleias, sejam vistos como os locais principais da greve, nos quais ela se efetiva e decisóes importantes são tomadas, isto é, onde a greve é "produzida”, não podemos perder de vista o papel também indispensável do apoio, encarregado, por exemplo, da alimentação da categoria durante aqueles dias, o que permitiu a "reprodução" da mobilização. Esposas de metalúrgicos passaram a levar refeições para a porta das fábricas. Muitas trabalhadoras ficaram responsáveis pela comida:

Tinha uma coisa de lanches que a gente preparava no sindicato e que a gente distribuía. Eu ajudava nisso também. No trabalho preparatório no sindicato, a gente fazia os plantóes. Ou a gente estava nos piquetes ou estava lá dentro. Estando lá dentro do sindicato, a gente entrava nas equipes. Ajudava. Eu ajudei a fazer cartazes, ajudei a fazer faixas, ajudei a distribuir comida [...]. Essa coisa de lanche, de cozinha, de fazer cartaz, de colar, de arrumar, de ajeitar, muitas mulheres faziam. Era possível que tivesse um ou outro homem, mas eu me lembro mais das mulheres. (Maria Teresa da Silva, 2018).

Como parte dessas estratégias utilizadas pelas grevistas, algumas cuidavam das crianças para que outras pudessem ir aos piquetes ou participar das assembleias. Essas redes de apoio mútuo entre as trabalhadoras acabavam também evitando o conflito entre casais militantes:

Quando você constrói uma família, o próprio marido fala: fica aí. Você aceita, se acomoda. Na luta maior, você está junta, mas isso acomoda um pouco. Eu sempre levei a Cassandra [filha dela] para as assembleias. Aí lá todo mundo é solidário sempre. Tem muitas crianças. As próprias militantes 
se ajudam. (Maria Amélia de Aquino, 2018).

Várias das entrevistadas recordaram, ainda, que, durante os meses que antecederam a greve, os banheiros femininos das fábricas metalúrgicas foram politizados. $\mathrm{Na}$ impossibilidade de discutirem a preparação para a greve em outros ambientes mais públicos das empresas, nos quais poderiam ser observadas, usavam como estratégia dotar o banheiro de uma dimensão política. Com gerentes e chefes homens, aquele era obviamente um lugar em que eles não entrariam, possibilitando a troca de ideias, de informaçóes e de materiais com relativa segurança.

Quando a gente começou mesmo, a gente tinha uns encontros no banheiro. Porque a gente não podia conversar. A gente ficava afiando e não podia conversar, não podia falar. A gente tinha um código que era assim: tantas horas no banheiro. Iam umas e voltavam. Daqui a pouco, espalhava e vinha outra galera. E a gente conversava. Nisso, já tinha um grupo de pessoas que estava participando também do movimento. Tinha uma área lá em Vicente de Carvalho que pegava as fábricas de lá e a gente era da comissão. Já tinham outras mulheres. Às vezes ia eu para falar. Às vezes ia uma outra, porque a gente não podia ficar no banheiro o tempo todo. A gente se revezava. Montou um esquema assim. E era tipo um jornal do banheiro. Era ali que a gente falava sobre a greve. (Maria Lúcia Guimarães, 2018).

Portanto, houve uma dupla participação das mulheres: nos palcos principais e nos bastidores da greve, como as entrevistadas assim consideraram. Ao olharmos para esses primeiros espaços, vemos na posição de liderança uma de nossas entrevistadas: Inês Guimarães. Era a única mulher integrante da Comissão Executiva de Salário (CES) e, em sua condição de liderança, falava ao microfone nas assembleias para os milhares de membros da categoria, inspirando, inclusive, as demais piqueteiras, como apareceu no depoimento delas, e incentivando a presença de mais trabalhadoras nas atividades grevistas. Além disso, podemos observar também centenas de mulheres nos piquetes, impedindo a entrada nas fábricas e mantendo a produção parada.

Simultaneamente, ao colocarmos o foco sobre os bastidores, vemos, ainda, mulheres cuidando da alimentação e das crianças e atendendo ao telefone do sindicato, que não parava, devido à necessidade de comunicação com os piquetes. E ainda tantas outras que não tomavam a palavra nas assembleias, mas que conversavam com outras mulheres para entender as diferentes concepçóes que seriam colocadas e fechar a posição da corrente política de que faziam parte, se fosse o caso. É o que relatam Telma e Edinalva: 
Eu nunca fui uma pessoa de falar muito em assembleia, porque a gente já tinha uma direção, já tinha definido quem faria isso. Mas no bastidor eu era uma pessoa muito consultada, muito ouvida, muito perguntada. Sempre tiveram esse cuidado de saber a minha opinião. (Telma do Amaral, 2017).

Tinha maior vontade de ir à tribuna falar, mas eu ficava com vergonha. Então, eu buscava ficar ali conversando com o pessoal que vinha das fábricas, para não sair, para esperar até o final. Vamos decidir, para votar pela greve. Esse papel nós fizemos muito bem. (Edinalva Menezes, 2017).

Após a continuidade da greve, aprovada na assembleia de sexta-feira, o sábado, dia 15 de setembro, foi de negociações tanto entre os grupos internos ao sindicato, isto é, os/as representantes das áreas, a CES e a direção, quanto deles com os patróes, além de os piquetes terem continuado. No domingo, ocorreu a assembleia pela manhá, na qual seria avaliada uma terceira proposta patronal colocada à mesa: $75 \%$ de aumento escalonado. Os ânimos estavam exaltados e havia muita divergência. Mais uma vez, a direção defendeu o fim da greve, entendendo ser necessário evitar uma iminente intervenção do regime militar no sindicato, uma vez que a Justiça já havia considerado a greve ilegal. Algumas lideranças, inclusive da oposição, eram da mesma opinião. No entanto, a posição que saiu vitoriosa entre os/as milhares de metalúrgicos/as que compareceram foi a das correntes mais radicais: não aceitar a proposta, continuar a greve e fazer uma nova assembleia na segunda-feira à noite.

No dia seguinte, como reação a essa decisão dos/as grevistas, houve enorme repressão policial aos piquetes, com dezenas de prisóes nas portas das fábricas, inclusive de Inês.

Eu fui presa na greve. Quando eu estava na porta da fábrica, a polícia veio: sai daí, porque você não pode ficar aí. Senão, a gente vai te prender. Eu disse: moço, a gente só está aqui por isso e isso. Me agarraram por aqui [aponta para o pescoço]. A sensação que eu tive é que fiquei com os pés no ar, mas não foi. Me botaram no camburão. Aí eu fui para a delegacia do Méier [...]. Dali eu fui direto para o DOPS [Departamento de Ordem Política e Social]. Eu fiz o depoimento e carceragem. Cheguei lá, estava uma cela com duas companheiras bancárias. Fiquei com elas dentro da cadeia. Da greve dos bancários, tinham elas duas. A outra cela era dos homens. Alguns companheiros souberam que eu fui presa e fizeram ser presos para encontrarem comigo dentro da delegacia. Eu sei que no final tinham oito companheiros lá presos. E cada um que chegava ia lá à minha cela. A gente abria a janelinha e começava: tá com medo, seu patrão... E cantava. (Maria 
Inês Guimarães, 2017).

Junto a esse, alguns outros fatores dificultaram a continuidade do movimento. Grande número de trabalhadores/as, favorável ao encerramento durante a última assembleia, resolveu voltar ao trabalho. A quantidade de pessoas que chegou para integrar os piquetes já estava também bem reduzida. Além disso, com esse mesmo entendimento, a direção do sindicato deixou de assumir o movimento, enfraquecendo a CES.

Nessa segunda-feira, dia 17, à noite, em uma assembleia tumultuada, a categoria decidiu encerrar a greve, aceitando a proposta patronal de um aumento escalonado de $75 \%$ e ciente de que os dias parados seriam descontados. Por um lado, então, esse desfecho teve duros impactos sobre a categoria devido às posturas do Ministério do Trabalho e do patronato. Inclusive, no dia 20 de setembro, o Sindicato dos Metalúrgicos do Rio de Janeiro denunciou que os patróes quebraram o compromisso de não demitirem ninguém até o final do ano. Foram dezenas de demissões sumárias, inclusive de algumas das piqueteiras entrevistadas.

Foram imediatas. Não teve jeito. A gente chegou, começou a trabalhar. Pouco tempo depois, veio a notícia: está demitida. (Maria de Fátima Santos, 2017).

Depois que passou a greve, eu fui a uma fábrica pedir emprego. Tinham vários trabalhadores lá pedindo emprego nesse dia. Era válvula de televisão. Então, o RH, o chefe lá, me colocou separada assim. Foi chamando mais umas oito pessoas. Ele me chamou e disse: não vou te dar a vaga, porque você fez piquete aqui na minha porta. Fez um esculacho total. Eu fiquei revoltada. Disse para ele: fiz greve com muita honra e vou continuar, porque isso é luta justa dos trabalhadores. E vim embora. (Carminda Ferreira, 2017).

No entanto, por outro lado, o movimento obteve importante vitória política e econômica, além de ter tido um caráter formativo impressionante, por representar a primeira experiência de greve e piquetes para grande parte desse conjunto de trabalhadores e trabalhadoras, resultando em crescimento da participação sindical e renovação dos quadros, segundo estas metalúrgicas:

Teve uma vitória. Ganhar 75\% para quem pede $83 \%$ é uma vitória. Depois, teve uma organização melhor do sindicato. Mesmo depois, claro que não tinha tanta gente, mas algumas pessoas foram um ganho para a causa. Um grupo grande de pessoas. Então, eu acho que foi uma vitória. (Maria Lúcia 
Guimarães, 2018).

A greve é um instrumento que os trabalhadores usaram ao longo do tempo de forma magnífica, eu acho, que foi o instrumento que deu condiçóes de se dar passos largos na organização e na conquista de direitos dos trabalhadores. A greve foi fundamental. Tanto é que a repressão é muito forte em cima da greve, porque os patróes sabem o poder que ela tem [...]. A força dos trabalhadores, essa coragem, essa uniáo, o poder da greve revela o que eu sinto e o que eu senti que foi a grande greve de que eu participei. (Doraci Barbieri, 2019).

\section{Conclusão}

A segunda metade da década de 1970 foi marcada pelo ascenso do movimento operário e sindical brasileiro. Após muitos anos sob forte pressão e obrigado ao trabalho silencioso dentro das fábricas e nos bairros, o sindicalismo nacional, escorado em fortes articulaçóes com os movimentos sociais e populares, reapareceu no cenário não apenas da luta entre capital e trabalho, mas ainda no contexto do debate político mais amplo. Se o ABC paulista abriu o caminho nesse processo, as mobilizaçóes que se seguiram por todo o país também fizeram parte relevante do ciclo de contestaçáo ali impulsionado.

Uma dessas mobilizaçôes foi certamente a greve metalúrgica de 1979 no Rio de Janeiro. Os resultados da pesquisa a apontaram como um marco de retomada da manifestação massiva e pública dos trabalhadores e das trabalhadoras desse estado. Apesar dos reveses causados pela ação do Ministério do Trabalho e do patronato, de não terem obtido os $83 \%$ de reajuste no salário, do desconto dos dias parados e das dezenas de demissóes, a greve, em geral, foi considerada extremamente bemsucedida por seus/suas integrantes. Isso porque conseguiram a adesão de mais de $80 \%$ de sua base no estado, a interrupção completa, por vários dias, da produção de diversos setores industriais importantes e a conquista de um aumento salarial de $75 \%$.

Esse sucesso pode ser explicado por fatores externos e internos ao movimento. Entre os externos, podemos elencar: a influência, sobretudo, das greves metalúrgicas do ABC paulista; e a articulação de várias categorias de trabalhadores/as, apoiandose mutuamente em suas greves e incorporando movimentos sociais. Já em relação aos fatores internos, é possível incluir: a existência de uma diretoria sindical fruto não mais de intervenção, mas eleita com apoio de grupos de oposiçáo, os quais 
tiveram maior abertura para participarem das diferentes atividades; as mobilizaçóes anteriores da FIAT no Rio de Janeiro em 1978 e 1979; o grande planejamento prévio da greve, responsável pela criação da Comissão Executiva de Salário (CES) e pela subdivisão do Rio de Janeiro em áreas, possibilitando ouvir as demandas locais; e, sem sombra de dúvidas, a indispensável dupla participação das trabalhadoras.

No que diz respeito a este último fator explicativo interno, as mulheres foram responsáveis por contribuiçóes em diferentes espaços, o que exigiu de muitas delas a construção de estratégias de articulação entre uma militância tão intensa, como a daqueles dias, e as atividades ligadas à família. Em primeiro lugar, elas estiveram nos palcos considerados principais, entre os quais os piquetes que pararam as fábricas. Em segundo lugar, no apoio, responsabilizaram-se, por exemplo, pela alimentação e pelo cuidado de seus filhos e dos de outros/as grevistas, politizando até mesmo os banheiros das fábricas.

Torna-se evidente, portanto, que, para compreender a ação política, fazse necessário observar historicamente todos esses espaços ao mesmo tempo, articulando militância e atividades familiares. Do contrário, dadas as desigualdades de gênero e a atribuiçáa diferenciada de papéis sociais aos sexos, ignorar o que seriam os bastidores tende a fazer com que a visão sobre a atuação mesmo dos homens - mas, sobretudo a respeito da participação das mulheres -, acabe por ficar imprecisa. Em outras palavras, não considerar, principalmente no caso delas, as práticas realizadas nessas duas esferas pode ter como consequência a falsa impressão de uma ação política menos expressiva das mulheres.

Nesse sentido, a metodologia da História Oral mostrou-se imprescindível, pois permitiu observar a ação coletiva da categoria metalúrgica em 1979 não apenas pela sua face mais pública, presente nas fontes escritas disponíveis (tais como jornais, atas e panfletos), mas também pela sua face mais privada. Esta última, registrada apenas na memória dessas trabalhadoras, ao revelar-se oralmente, tornou possível compreender a greve por outros ângulos e creditar grande parte de seu sucesso a atuação das mulheres. Devido à militância nos bastidores e nos piquetes, elas efetivamente pararam as fábricas e colaboraram para o ciclo de mobilizaçóes que, no final dos anos 1970, desafiou fortemente o regime ditatorial, contribuindo para o processo de redemocratização na década que se abria.

\section{Referências}

BLANCO, Esmeralda. O trabalho da mulher e do menor na induistria paulistana (18901920). Petrópolis: Vozes, 1982. 
BLAY, Eva Alterman. Trabalho domesticado: a mulher na indústria paulista. São Paulo: Ática, 1978.

CASTRO, Mary Garcia. O conceito de gênero e as análises sobre mulher e trabalho: notas sobre impasses teóricos. Caderno CRH, Salvador, n. 17, p. 80-105, 1992.

CECUT. A greve de setembro dos metalúrgicos do Rio de Janeiro - 1979. Depoimentos. Rio de Janeiro: Centro Cultural dos Trabalhadores - CECUT, 1981.

CRENSHAW, Kimberlé. Documento para o encontro de especialistas em aspectos da discriminação racial relativos ao gênero. Estudos Feministas, Florianópolis, v. 10, n. 1, p. 171-188, 2002.

DEL PRIORE, Mary (Org.). História das mulheres no Brasil. São Paulo: Contexto/ Edunesp, 1997.

DIEESE. Perfil das trabalhadoras metalúrgicas, 2015. Disponível em: <http://www. cnmcut.org.br/midias/arquivo/212-perfil-das-trabalhadoras-metalurgicas-2015.pdf>. Acesso em: 4 dez. 2020.

FERREIRA, Marieta de Moraes; AMADO, Janaina (Org.). Usos \& abusos da História Oral. Rio de Janeiro: FGV, 2006.

HALBWACHS, Maurice. A memória coletiva. São Paulo: Vértice, 1990.

HIRATA, Helena. Divisão sexual do trabalho profissional e doméstico: Brasil, França, Japão. In: COSTA, Albertina de Oliveira; SORJ, Bila; BRUSCHINI, Cristina; HIRATA, Helena. (Org.). Mercado de trabalho e gênero: comparaçóes internacionais. Rio de Janeiro: Editora FGV, 2008. p. 263-278.

; KERGOAT, Danièle. Novas configuraçôes da divisão sexual do trabalho. Cadernos de Pesquisa, São Paulo, v. 37, n. 132, p. 595-609, 2007.

KERGOAT, Danièle. Dinâmica e consubstancialidade das relaçóes sociais. Novos Estudos Cebrap, São Paulo, n. 86, p. 93-103, 2010.

KRISCHKE, Paulo (Org.). Brasil: do "milagre” à “abertura”. São Paulo: Cortez, 1982.

LAPA, Thaís de Souza. O gênero do trabalho operário: condiçôes de trabalho, divisão sexual e práticas sociais em indústrias metalúrgicas dos segmentos automotivo e eletroeletrônico. Tese (Doutorado em Ciências Sociais) - Unicamp, Campinas, SP, 2019.

LEITE, Miriam Moreira (Org.). A Condição feminina no Rio de Janeiro, século XIX. Sáo 
Paulo: Hucitec, 1984.

MARTINHO, Francisco Carlos Palomanes. Sindicato, ditadura e transição: continuidades e descontinuidades no corporativismo brasileiro (1974-1984). Análise Social, Lisboa, v. 52, n. 224, p. 634-661, 2017.

PENA, Maria Valéria Junho. Mulheres e trabalhadoras: presença feminina na constituição do sistema fabril. Rio de Janeiro: Paz e Terra, 1981.

PEREIRA, Jaqueline Silva Figueiredo. O modelo de competência e as implicaçōes na divisão sexual do trabalho no processo de reestruturação da produção. Dissertação (Mestrado em Educação) - UFMG, Belo Horizonte, MG, 2004.

POLLAK, Michael. Memória, esquecimento, silêncio. Estudos Históricos, Rio de Janeiro, v. 2, n. 3, p. 3-15, 1989.

SADER, Eder. Quando novos personagens entraram em cena. Rio de Janeiro: Paz e Terra, 1988.

SAFFIOTI, Helieth. A mulher na sociedade de classes: mito e realidade. São Paulo: Quatro Artes, 1969.

. Violência de gênero: o lugar da práxis na construção da subjetividade. Lutas Sociais, São Paulo, n. 2, p. 59-79, 1997.

SAMPAIO, Darli de Fátima. Relaçôes de gênero na indústria automotiva. A problemática da divisão sexual do trabalho e da visão essencializada da mulher. Um estudo de caso. Dissertação (Mestrado em Sociologia) - UFPR, Curitiba, PR, 2007.

SANTANA, Marco Aurélio. Homens Partidos: comunistas e sindicatos no Brasil. São Paulo/Rio de Janeiro: Boitempo/UniRio, 2001.

SOIHET, Rachel. Condição feminina e formas de violência: mulheres pobres e ordem urbana 1890-1920. Rio de Janeiro: Forense Universitária, 1989.

; PEDRO, Joana Maria. A emergência da pesquisa da história das mulheres e das relações de gênero. Revista Brasileira de História, São Paulo, vol. 27, n. 54, p. 281-300, 2007.

SOUZA-LOBO, Elizabeth. A classe operária tem dois sexos. São Paulo: Editora Brasiliense, 1991.

TORREÃO, Rita Célia Magalhães. A greve nasce na fábrica - metalúrgicos no Rio de 
Janeiro (1979). Dissertação (Mestrado em Sociologia) - UFRJ, Rio de Janeiro, RJ, 1986.

WEFFORT, Francisco. Participação e conflito industrial: Contagem e Osasco, 1968. São Paulo: Cebrap, 1972.

\section{Fontes orais}

AMARAL, Telma do [59 anos]. [nov. 2017]. Entrevistadores: Marco Aurélio Santana e Alexandre Barbosa Fraga. Rio de Janeiro, RJ, 28 nov. 2017.

AQUINO, Maria Amélia de [67 anos]. [jan. 2018]. Entrevistadores: Marco Aurélio Santana e Alexandre Barbosa Fraga. Rio de Janeiro, RJ, 30 jan. 2018.

BARBIERI, Doraci [73 anos]. [set. 2019]. Entrevistadores: Marco Aurélio Santana e Alexandre Barbosa Fraga. Rio de Janeiro, RJ, 20 set. 2019.

FERREIRA, Carminda (Carminha) [68 anos]. [nov. 2017]. Entrevistadores: Marco Aurélio Santana e Alexandre Barbosa Fraga. Rio de Janeiro, RJ, 28 nov. 2017.

GUIMARÃES, Maria Inês (Inês) [61 anos]. [nov. 2017]. Entrevistadores: Marco Aurélio Santana e Alexandre Barbosa Fraga. Rio de Janeiro, RJ, 29 nov. 2017.

GUIMARÃES, Maria Lúcia [61 anos]. [mar. 2018]. Entrevistadores: Marco Aurélio Santana e Alexandre Barbosa Fraga. Rio de Janeiro, RJ, 28 mar. 2018.

LOUREIRO, Jaqueline [57 anos]. [jan. 2018]. Entrevistadores: Marco Aurélio Santana e Alexandre Barbosa Fraga. Rio de Janeiro, RJ, 31 jan. 2018.

MENEZES, Edinalva [64 anos]. [dez. 2017]. Entrevistadores: Marco Aurélio Santana e Alexandre Barbosa Fraga. Rio de Janeiro, RJ, 6 dez. 2017.

SANTOS, Georgina dos [66 anos]. [jan. 2018]. Entrevistadores: Marco Aurélio Santana e Alexandre Barbosa Fraga. Rio de Janeiro, RJ, 31 jan. 2018.

SANTOS, Maria de Fátima (Fátima) [66 anos]. [dez. 2017]. Entrevistadores: Marco Aurélio Santana e Alexandre Barbosa Fraga. Rio de Janeiro, RJ, 13 dez. 2017.

SILVA, Maria Teresa da (Teca) [62 anos]. [abr. 2018]. Entrevistadores: Marco Aurélio Santana e Alexandre Barbosa Fraga. Rio de Janeiro, RJ, 20 abr. 2018. 
Resumo: Este artigo objetiva compreender a participação das mulheres trabalhadoras na greve da categoria metalúrgica do Rio de Janeiro de 1979, ocorrida ainda durante o regime militar brasileiro. A partir do uso da metodologia da História Oral, foram realizadas entrevistas com onze mulheres que fizeram parte ativamente desse movimento, as chamadas piqueteiras, como ficaram conhecidas. Os resultados da pesquisa apontaram a greve dos/ as metalúrgicos/as de 1979 como um marco de retomada da mobilizaçáo massiva e pública da classe trabalhadora no estado do Rio de Janeiro, que teria seu ápice nos anos 1980. As mulheres que participaram da greve, além de terem composto o que seria o setor de apoio, atuaram diretamente nos piquetes que pararam as fábricas. Para isso, elas precisaram articular as açóes do movimento sindical ao cuidado da casa e dos filhos, o que deu origem a estratégias próprias para garantir a efetividade dessa participação.

Palavras-chave: Mulheres. Gênero. Greve. Metalúrgicos. História Oral.

\title{
The picketers: women and political participation in the 1979 metalworkers strike in Rio de Janeiro
}

\begin{abstract}
This article aims to understand the participation of women metalworkers in the 1979 strike in Rio de Janeiro, occurred during the brazilian military regime. Using the methodology of Oral History, interviews were conducted with eleven women who were actively part of this movement, the so-called women picketers, as they became known. The research results pointed to the 1979 strike of the metalworkers as a milestone in the resumption of massive and public mobilization of the working class in the state of Rio de Janeiro, which was to peak in the 1980s. The women who participated in the strike, besides having composed the support sector, acted directly in the pickets that stopped the factories. For this, they needed to articulate the actions of the trade union movement to care for the home and children, which gave rise to their own strategies to ensure the effectiveness of this participation.
\end{abstract}

Keywords: Women. Genre. Strike. Metalworkers. Oral History.

Recebido em 10/08/20

Aprovado em 09/11/20 